\title{
La Tablada en enero de 1989 y sus efectos e impacto en Córdoba. Sobre la (re) estigmatización de las militancias en la historia reciente
}

\author{
[La Tablada in January 1989 and its Effects and Impact in Córdoba. \\ About the (re) Stigmatization of Militancies in Recent History]
}

\author{
Ana Carol Solis \\ (Universidad Nacional de Córdoba) \\ acarolsolis@yahoo.com.ar
}

\begin{abstract}
Resumen:
Las múltiples incidencias producidas a partir del acontecimiento de La Tablada, en enero de 1989, sobre las militancias en general y concretamente en Córdoba se reconstruyen mediante el análisis de las diferentes acciones y repercusiones institucionales y políticas que provocó. En particular, el artículo se interroga por las acciones de (re)estigmatización de las militancias ubicadas dentro de un universo político ideológico afín y/o cercano al grupo militante identificado como iniciador del evento, pero también para una cartografía más amplia de actores políticos y militancias organizadas. La contracara de esa estigmatización se analiza en el retorno de discursos de legitimación de la acción estatal represiva, aún atisbado el uso reiterado de metodologías afines al terror de Estado en democracia.
\end{abstract}

Palabras Claves: Militancias - $(\mathrm{Re})$ Estigmatización - La Tablada - Córdoba Historia Reciente

\begin{abstract}
:
The numerous effects produced thereafter the event of La Tablada in January 1989, about the militancy in general and particularly in Córdoba, are being rebuilt through the analysis of the different actions and through the institutional and political impacts that they caused. In particular, this article questions the actions of (re)stigmatizing the militancy present into a political and ideological space, related to the militant groups identified with the event. Also, this article pays attention to a more extensive bunch from political actors and organized militancy. The reverse of that stigmatization is analysed due to the return of some speeches that legalize the repressive estate action, peeking the repeated use of some methodologies related to the state terrorism in democracy.
\end{abstract}

Key Words: Militancy - (Re) Stigmatizing - La Tablada - Córdoba - Recent History

Recibido: $24 / 7 / 2018$

Evaluación: 25/9/2018

Aceptado: 27/5/2019

Anuario de la Escuela de Historia Virtual - Año 10 - N 15 - 2019: pp. 51-67.

ISSN: 1853-7049

http://revistas.unc.edu.ar/index.php/anuariohistoria 


\section{La Tablada en enero de 1989 y sus efectos e impacto en Córdoba. Sobre la (re) estigmatización de las militancias en la historia reciente}

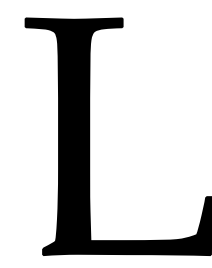

os años ochenta del siglo XX en Argentina configuraron una década signada por el final de la dictadura y la reapertura de procesos democratizadores, pero también jalonada por una creciente amenaza de reversión autoritaria, las complejidades de las herencias dictatoriales y los sucesivos fracasos en establecer opciones superadoras. Al ocaso de esa década convulsionada, se produjo un evento inesperado: el ataque por parte de un grupo militante, el Movimiento Todos por la Patria, a un cuartel militar -el RIM 3 (Regimiento de Infantería Mecanizado 3 General Manuel Belgrano)- en la localidad de La Tablada de la provincia de Buenos Aires. Según interpretaciones posteriormente difundidas, los militantes actuaron amparados en una lectura de coyuntura que preveía una nueva intentona golpista, proponiéndose tomar las armas para desarticular esos planes y sumar apoyos populares en pos de un horizonte insurreccional. En efecto, de manera inesperada el 23 de enero de 1989 este nuevo acontecimiento irrumpió en medio de la creciente descomposición de los apoyos a la gestión del presidente Alfonsín. La Tablada, un suceso que fue denominado como rebelión, alzamiento, intentona, copamiento, entre otros, se convertiría en un evento parteaguas de la política en diferentes planos y fue leído casi unánimemente como un momento de necesaria ruptura con el pasado reciente. Lo sucedido entonces ha sido tematizado en bibliografía específica ${ }^{1}$ y se ha mantenido, con oscilaciones, en agenda principalmente por las consecuencias jurídico-legales que tuvo. Este año se realizó finalmente el juicio que culminó con la primera condena a un responsable de cometer delitos contra los prisioneros en oportunidad de reprimir el movimiento. ${ }^{2}$

En su contemporaneidad el intento de copamiento generó efectos públicos y repercusiones varias, constituyendo una nueva divisoria en relación a la aceptación o rechazo del uso político de la violencia. Esa coyuntura se enlaza además con otros procesos que han constituido nuestro punto de interés reciente, como fueron las reconfiguraciones de la militancia en la posdictadura y transición analizando su participación en las disputas por la democratización, específicamente desde el abordaje sociohistórico de las experiencias de Barrial y el Movimiento

\footnotetext{
${ }^{1}$ Una revisión mínima de la bibliografía en: Hilb, 2007; Ceresole, 1989; Mattini, 2003; Gorriarán, 2003; Montero, 2012; Celesia y Waisberg, 2013.

${ }^{2}$ El 12 de abril de 2019 el TOF 4 de San Martín, Buenos Aires, sentenció a cadena perpetua al ex general Alfredo Arrilaga por homicidio agravado contra José Díaz quien permanece desaparecido en ocasión de la represión al intento de copamiento de La Tablada. En dicho juicio se logró desmontar las versiones oficiales, al comprobar que hubo delitos graves, ocultamiento y tergiversación de lo allí ocurrido en relación con las torturas, asesinatos y desapariciones cometidas contra los militantes del MTP en las acciones de recuperación del cuartel. Arrilaga ya tenía cinco condenas previas por delitos de lesa humanidad. Aún queda pendiente conocer y juzgar lo ocurrido con las otras tres víctimas de desaparición no incluidas en este proceso: Iván Ruiz, Francisco Provenzano y Carlos Samojedny.
} 
Cordobés (en adelante MoCo) para los años ochenta en la ciudad de Córdoba, Argentina, que conformó el núcleo principal de mi tesis doctoral. ${ }^{3}$ Este movimiento integró el Movimiento Todos por la Patria, igualmente ligado a una experiencia editorial como fue la revista Entre Todos, y explicitó esa pertenencia en la campaña del año 1987. Con posterioridad, el grupo de Córdoba se habría separado de su referencia nacional y hacia 1989 ya no serían parte de la misma cuando se sucedan los acontecimientos que aquí analizamos y que fueran protagonizados por integrantes de esa agrupación. Esa trama lleva a preguntarnos por el haz de efectos públicos y el impacto que produjo el acontecimiento La Tablada, en particular para ciertas militancias como las reunidas en el MoCo.

En ese marco, en este artículo analizamos las repercusiones, tomas de posición y acciones que generó La Tablada en el escenario nacional y en Córdoba, a partir de fuentes hemerográficas, ${ }^{4}$ para luego dar lugar a algunos de los impactos que la configuración resultante de este acontecimiento implicó para ciertas militancias. Se procura con ello aportar a su historia reciente al considerar de manera conjunta los desafíos y reconfiguraciones que la apertura de un tiempo posdictatorial había implicado para las militancias viejas y nuevas, sumado a aquellos que se fueron conformando con el devenir de los años ochenta. Se sostiene que La Tablada, en tanto acontecimiento, produjo múltiples efectos públicos y acciones políticas que impactaron no solo en una masiva y sostenida condena a la violencia como política, en consonancia con ciertos consensos que se habían ido consolidando en la transición, sino también al recrear nuevas estigmatizaciones hacia ciertas militancias que se construyeron como peligrosas y no deseables y, en consecuencia, destinatarias de su investigación, persecución o posible judicialización; por lo que haríamos referencia a un haz de efectos discursivos y de acciones que afectaron a las militancias e incidieron en sus prácticas. Ello ocurrió especialmente con las militancias ubicadas dentro de un universo político ideológico afín y/o cercano al grupo militante identificado como iniciador del evento, pero también con una cartografía más amplia de actores políticos y militancias organizadas. Un segundo efecto que nos interesa destacar es que los modos de inscripción pública predominantes en la prensa consultada respecto del operativo de recuperación del cuartel aportaron también a circular discursos que legitimaron el uso de la violencia represiva, incluso por sobre las denuncias de comisión de delitos que ya entonces se hicieron conocidas y que podrían asemejarse a algunas de las metodologías desplegadas por el terror de Estado en dictadura.

\footnotetext{
${ }^{3}$ La revista Barrial constituyó una experiencia de periodismo anclada en los procesos territoriales que resultó fundamental para relevar la participación en las disputas por la democratización en y desde los barrios de la ciudad de Córdoba. La iniciativa correspondió a un grupo de militantes pertenecientes a diferentes expresiones de la militancia revolucionaria que habían sido represaliados en dictadura. Asimismo conformó un proyecto de articulación política que, junto a otras redes activadas y sujetos políticos con presencia barrial, conformó el Movimiento Cordobés de cara a las elecciones municipales de 1987. Este artículo toma especialmente parte de los desarrollos del capítulo 6 de mi tesis doctoral, al que se le han incorporado aportes sugeridos por los evaluadores anónimos, a quienes agradezco. Solis, 2018.

${ }^{4}$ Consultamos La Voz del Interior, en adelante LVI.
} 


\section{Entre acciones y repercusiones}

Un primer relevamiento de las informaciones publicadas muestra que, salvo muy escasas excepciones, la cobertura nacional y local iba en la misma sintonía de ratificar lo que se fue construyendo como la versión oficial de los sucesos, aquella que se basaba principalmente en los informes oficiales provistos por las propias fuerzas represivas. Esto es, el asalto de un grupo político (setentista) ${ }^{5}$ que por las armas intentó copar un regimiento militar. Rápidamente la reposición de términos como guerrilleros izquierdistas, grupo terrorista, extremistas, subversivos -y las referencias concretas al ERP en un primer momento que luego serían al Movimiento Todos por la Patria (en adelante MTP) ${ }^{6}$ instalaron el hecho como el desfasado $\mathrm{u}$ anacrónico uso de la violencia política por un reducido grupo que atentó "contra la democracia", siendo las fuerzas militares y policiales las que heroicamente repelieron la intentona. Publicaba LVI:

La violencia del combate no guarda precedentes, aún en la cruenta historia de la subversión en la Argentina. El último antecedente de la guerrilla urbana con una acción de este tipo se remonta a la Navidad de 1975, cuando un centenar de guerrilleros pertenecientes al ERP y Montoneros, asaltó el cuartel "Domingo Viejobueno", en la localidad bonaerense de Monte Chingolo.7

No es objeto de este apartado discutir la veracidad de las diferentes explicaciones de los contemporáneos a La Tablada ni tampoco de las producidas, con posterioridad, tanto por estudios expertos como por la propia justicia nacional e internacional. Sí lo es mostrar el modo en que lo noticiable, en este caso en LVI, mostró/marcó ciertos contextos de lectura de un episodio que prontamente generó un amplio y extendido rechazo por parte de las dirigencias políticas y demás referentes del proceso político. Marta Philp ha incluido estos sucesos en su estudio sobre los procesos de legitimación política en la historia reciente de Córdoba, en particular dentro de los vínculos entre memoria y política en relación al "olvido y la superación del pasado como requisito para la modernización". En efecto, analiza las repercusiones y tomas de posición de este evento sucedido en enero de 1989 entre dirigentes y fuerzas políticas locales y nacionales, señalando acontecimientos sobre los que volveremos para entramarlos en una nueva preocupación; esto es, el impacto en las militancias (Philp, 2009, pp. 426-429).

En Córdoba, además de fortalecerse el control policial sobre edificios claves como EPEC la empresa de electricidad provincial-, Obras Sanitarias y otros vinculados a la provisión de servicios, la escalada de rechazos fue in crescendo. El gobierno provincial expresó su más enérgico repudio a quienes atentaron contra la democracia y se condolía por la muerte de los

\footnotetext{
${ }^{5}$ Utilizo cursiva para expresiones nativas que aparecen en las fuentes consultadas y cuando se trate de resaltar una expresión dentro de un fragmento de cita. Por el contrario, cuando sean citas completas utilizaré comillas.

${ }^{6}$ Según la primera plana del diario, los interrogatorios e identificación de algunos cuerpos permitieron asociarlos como "una suerte de reagrupamiento de extrema izquierda, vinculado al extinguido Ejército Revolucionario del Pueblo", LVI, 24/1989, p. 1.

${ }^{7}$ LVI, 24/1/1989, p. 1.
} 
efectivos militares y policiales. ${ }^{8}$ Estos dos elementos fueron recurrentes en la discursividad de los repudios: 1) aseverar que se trataba de "un golpe a la democracia" conquistada en 1983 y 2) señalar solamente el dolor por la muerte de los últimos, pese a que el número de militantes muertos fue varias veces superior al de los uniformados, jerarquizando las muertes resultantes $\mathrm{y}$, sobre todo, contribuyendo a relegitimar a las fuerzas armadas (y de seguridad) en el final de una década que los había tenido como protagonistas de una creciente amenaza de reversión autoritaria. Recordemos que la negativa a continuar las políticas oficiales de revisión de responsabilidades en la represión dictatorial más allá del Juicio a las Juntas de Ex Comandantes se expresó con los denominados "alzamientos carapintadas". 9 Ese clima golpista que se insinuó reiteradas veces bajo el gobierno de Alfonsín y la acción militar de oponerse a la continuidad de los juzgamientos por los delitos cometidos en dictadura son parte del contexto que precisa ser repuesto para situar la amplitud de los rechazos y efectivamente la sorpresa que la acción armada del MTP produjo en amplios sectores, incluso con cierta sintonía progresista y del campo de las izquierdas.

Ahora bien, retomando la discursividad que tendió a legitimar la acción represiva estatal y a jerarquizar a los muertos, esta incluye la voz del presidente Alfonsín:

[en La Tablada] a cada momento recogíamos las evidencias del coraje de quienes hoy merecen el reconocimiento de la patria. Hemos podido repeler ese acto subversivo porque hubo hombres en disposición y con la decisión de pelear. [...] Hubo argentinos que murieron para que otros argentinos pudiésemos mantener nuestra libertad, preservar nuestro estilo de vida, nuestra convivencia [...] La sociedad no tolera más violencia, cualquiera sea su signo. Sabe que si no cortamos este encadenamiento de violencia, que genera más violencia, correremos gravísimos riesgos. [...] Ahora la democracia ha enfrentado la demencia, la acción sanguinaria de quienes recurrieron a la violencia como método de acción política, cuando este proceder elitista, absurdo y atroz ha sido rechazado claramente por todos los argentinos. ${ }^{10}$

Sus expresiones delimitaban claramente cuál(es) violencia(s) eran permitidas ${ }^{11}$ y la(s) que no lo eran. Es decir, la acción represiva como expresión del uso de la violencia estatal fue aceptada al mismo tiempo en que se deslegitimaba y rechazaba el uso de la violencia en manos de quienes no tenían esa condición estatal. Estas definiciones se complementaron con creaciones institucionales nuevas, como fue la conformación de un Consejo de Seguridad Nacional, ante las críticas difundidas por la falta de previsión estatal respecto de este acontecimiento. Para los analistas de la defensa y la seguridad, desde 1983 se fue construyendo un consenso básico referido a la prescindencia militar en cuestiones de seguridad interior. Ese

\footnotetext{
${ }^{8}$ Al segundo día, una vez culminadas las acciones, se contabilizaba un total de 38 muertos y 63 heridos. De ese universo, se afirmaba que al menos 28 eran los muertos del "terrorismo", siete militares y un policía, y 14 detenidos tras treinta horas de "fragorosos combates".

${ }^{9}$ El Comité provincial de la UCR se expresó de modo similar, repudiando un copamiento que abonaba la teoría de los demonios por dar credibilidad a quienes sostienen que la democracia no lograba establecer el orden. LVI, 24/1/1989, p. 9.

${ }^{10}$ LVI, 25/1/1989, pp. 2-3.

${ }^{11}$ Utilizo la expresión "permitidas" haciendo una resignificación de los términos de Tilly (2006) para quien existen en cada régimen actividades políticas permitidas, toleradas y prohibidas. En este caso, procuro mostrar que la violencia represiva del Estado tiene también diferentes construcciones históricas en su aceptación o rechazo.
} 
consenso se habría cristalizado en leyes claves, como la ley de Defensa de abril de 1988 y la ley de Seguridad Interior de 1992 (Sain, 2018; Anzelini, 2019). En efecto, en 1988 se aprobó la ley $N^{\circ} 23.554$ de Defensa Nacional considerada un hito en la desmilitarización de la seguridad, al deslindar que las Fuerzas Armadas se ocuparían de la defensa y las Fuerzas de Seguridad federales de la seguridad interior. ${ }^{12}$

Volviendo al rechazo a la acción armada, dentro de sentidos similares se expresaron en Córdoba cuerpos colegiados e instancias de representación política. Así el Consejo de los Partidos Políticos, creado en 1987, la Mesa de Gestión y Asesoramiento, la legislatura provincial y fuerzas partidarias expresaron repudios enérgicos a la acción que se calificaba como terrorista, remarcando su compromiso con la democracia. Por su parte, el Partido Intransigente solicitó información exhaustiva y que se actuara en el marco de la Ley de Defensa de la democracia ${ }^{13}$ mientras la Izquierda Unida denunciaba que estos hechos confundían y solo servían para fortalecer el aparato represivo y que sería "usada por algunos sectores para desprestigiar a la izquierda". ${ }^{14}$ También expresaron repudios el Partido Socialista Popular y el Movimiento de Integración y Desarrollo, el comité capital de la UCR, el Partido Socialista Auténtico, la Fuerza Federal Republicana, el Partido Obrero, el Movimiento Todos por la Patria, y el Partido de Acción Popular..$^{15}$ La mención al MTP es notable entre estos primeros apoyos a las posiciones mayoritarias, por cuanto todavía no estaba muy clara la asignación de autoría a integrantes activos de su núcleo nacional respecto de los hechos de La Tablada.

Dentro de las personalidades locales y organizaciones, se expresaron el rector de la UNC Dr. Rébora -quien había presidido la Delegación Córdoba de la CONADEP en 1985- el titular del Tribunal Superior de Justicia Horacio Roitman, la Bolsa de Comercio de Córdoba, el Sindicato de Luz y Fuerza, la Unión Obrera Gráfica, CISPREN -sindicato de trabajadores de prensa-, SUOEM -de los municipales-, la Asociación Gremial de Empleados de Comercio y la Federación Médico Gremial de la provincia. Igualmente se expresaron la Asociación Bancaria, la Asociación Gremial de Empleados del Poder Judicial, la UEPC -sindicato de los docentes- y el Sindicato de Trabajadores de la Industria de la Alimentación. ${ }^{16}$ LA CGT

\footnotetext{
${ }^{12}$ Es preciso señalar que su reglamentación ocurrió recién durante el gobierno de Kirchner (Anzelini, 2019). En la ley $\mathrm{N}^{\circ} 24.059$ de 1992 se establecieron las ocasiones excepcionales en las que las Fuerzas Armadas podrían intervenir en asuntos de seguridad interior: a pedido del comité de crisis, por el ataque armado a una unidad militar y por un estado de conmoción interior que sobrepase al sistema policial federal, bajo el estado de sitio (Sain, 2018).

${ }^{13}$ Con dicha expresión pudo aludir a dos leyes: la ya comentada ley de Defensa Nacional de 1988 que efectivamente era una ley de la democracia que desandaba la concepción de defensa anteriormente vigente, pero también a otra creación de la posdictadura: la ley N²3.077 de agosto de 1984, popularizada como ley de defensa de la democracia. La misma derogaba parte de las leyes dictatoriales y contenía un sentido restituyente, al considerar vigentes algunas leyes previas y ciertos artículos del Código Penal. Era pródiga, además, en precisar la aplicación de justicia, en particular respecto de los procedimientos y normas procesales. De igual modo, especificaba las penalidades para determinados delitos asociados al ataque a la democracia y sus instituciones. Contenía, en todos sus términos, una voluntad de ruptura con la normatividad previa y aumentaba los castigos por no cumplimiento y observancia de la Constitución Nacional.

${ }^{14}$ LVI, 25/1/1989, p. 8.

${ }^{15}$ Ibídem, destacado nuestro.

${ }^{16}$ En días seguidos se conocieron los repudios del fiscal general de la provincia, Cortéz Olmedo, diferentes comités y referentes del radicalismo, así como representantes de diferentes líneas internas del peronismo y unidades básicas.
} 
Chacabuco fue más contundente, al calificarlos de forajidos y estimar que "el salvajismo del procedimiento pone de manifiesto los oscuros designios de instigadores y ejecutores" ${ }^{17}$

Resulta interesante señalar que los organismos de derechos humanos de Córdoba también expresaron un repudio en un documento conjunto a "este nuevo atentado contra el orden constitucional" firmado por las organizaciones que habían construido una tradición de lucha común desde tiempos de la dictadura: “Abuelas de Plaza de Mayo, Familiares de Detenidos y Desaparecidos por Razones Políticas, Liga Argentina por los Derechos del Hombre, Servicio Paz y Justicia y Asamblea Permanente por los Derechos Humanos". ${ }^{18}$

Por tratarse además de un tiempo preelectoral, los dos candidatos más importantes a la presidencia, Eduardo César Angeloz (UCR) -de gira por Europa- y Carlos Saúl Menem (PJ) suspendieron sus actos de campaña en los días inmediatos, aunque en breve reanudaron su agenda. La relación entre los dos principales partidos nacionales luego se tornó en una disputa pública por las acusaciones de Menem respecto a los vínculos entre el gobierno radical y el grupo atacante, denunciando que se trataba de un hecho para perjudicar electoralmente al peronismo.

De esta coyuntura compleja en el marco de un gobierno nacional que perdía crecientemente apoyos, principalmente por los desaciertos de la política económica, me interesa profundizar en dos aspectos que se derivan de la situación iniciada con La Tablada. Por un lado, cómo se produjo una acelerada recomposición de los discursos de legitimación pública respecto de la capacidad represiva (y punitiva) del Estado en democracia y los términos en los que esta se promovió y, por otro, los efectos e impactos para la militancia en general y para el arco ideológico en el que se ubicaba el proyecto político del Movimiento Cordobés, por la anterior identificación y proximidad con el MTP, una vez que se precisó la filiación política de los militantes.

Respecto de la capacidad represiva del Estado, esta había sido el principal eje articulador de la política dictatorial, incluso adelantado al tramo final del tercer gobierno peronista entre 1973 y 1976. A contrapelo de lo ocurrido con otras capacidades reguladoras de lo público estatal, la dimensión represiva se había agigantado en el pasado cercano y, justamente por ello, había producido una suerte de extrañamiento de los ciudadanos respecto de un Estado que en lugar de garante se había convertido en administrador del terror. Ello habría operado negativamente en la legitimación pública de esa capacidad estatal, atrapada en la posdictadura entre los avatares de juzgar a los responsables y acometer la subordinación de los militares al poder civil. Ahora, desde la reinstitucionalización iniciada en 1983, La Tablada fue el primer conflicto en el que la orden fue reprimir, a diferencia de los acontecimientos sucedidos por los alzamientos militares denominados contemporáneamente como "carapintadas" que solo fueron repelidos con violencia bajo la presidencia de Menem, fuera de nuestro marco temporal de análisis. ${ }^{19}$ Pero además, hubo una decidida acción pedagógica que fortalecía ese rechazo a

\footnotetext{
${ }^{17}$ LVI, 27/1/1989, p. 7.

${ }^{18}$ LVI, 26/1/1989, p. 4. Volveremos luego con una interpretación más general respecto a los posicionamientos locales y nacionales del movimiento.

${ }^{19}$ Sobre los levantamientos carapintadas, ver Sain, 1994.
} 
la violencia en manos no estatales, por ejemplo al realizarse una visita de legisladores nacionales al cuartel -de la UCR, el PJ, la UCeDe e incluso del PI- que pudieron observar el estado del mismo, incluida una exposición de las armas usadas "por el grupo terrorista" y la difusión de los relatos de los hombres de seguridad que participaron del mismo, hechos que recuerdan los operativos de las fuerzas represivas en los años setenta.

Fuera de estos efectos discursivos y delimitando las acciones y prácticas desarrolladas por diferentes poderes del Estado, a los acontecimientos de La Tablada sucedieron allanamientos, detenciones con panfletería asociada al MTP, pero también algunas tímidas denuncias de un trato cruel a los atacantes que por entonces fue clandestino y que solo después los familiares de las víctimas, incluidas aquellas que hasta hoy permanecen desaparecidas, han podido denunciar en la justicia. Esto es, como en el pasado dictatorial, una parte de la represión fue pública y formalmente asumida y otra, que reponía las torturas, el asesinato y la desaparición, fue igualmente clandestina y, por ende, desligada oficialmente del accionar estatal. Como represión (pública) las informaciones destacaban la eficiencia de las fuerzas oficiales frente al ataque sufrido -se citaron frecuentemente expresiones del siguiente tono: "respuesta contundente" y dentro "del marco de la ley"- en línea con aquellas que destacaban la heroicidad de los militares y policías que participaron de la recuperación del cuartel.

En términos de Tilly (2006 y 2007), podríamos decir que la operación reafirmó a quienes eran los especialistas en violencia, entre quienes integra a las fuerzas estatales encargadas del monopolio de la violencia, al final de una década en la que la corporación militar y el ejecutivo nacional habían tenido serios enfrentamientos por los márgenes de la subordinación civil de la primera y los límites y alcances de las políticas de revisión del pasado que proponía el segundo. La construcción de esa nueva representación suturante, en la que el ataque a los militares era un ataque a la nación toda, fue sobreimpresa (resaltada y afirmada) cuando se conocieron las filiaciones políticas partidarias de los militantes que iniciaron el intento de copamiento.

En efecto, con relación a las responsabilidades en La Tablada, el 26 de enero se publicaba finalmente la identidad política de los atacantes del cuartel. Se había reconocido entre los "abatidos" a Jorge Baños, referente nacional del MTP y quien había tenido participación activa en el CELS. Esa identificación política tenía efectos directos para todo el arco de militancias reunido en lo que fue conocido como la experiencia del MTP.

Para quienes fueron el grupo iniciador y principales referentes e integrantes del Movimiento Cordobés esto planteaba un dilema central: diferenciar su proyecto político de la organización nacional que centralizaba los mayores repudios en democracia, cuestión que se analizará luego. El primer repudio del Movimiento Cordobés se publicó como mención dentro de un grupo de rechazos que incluyeron a expresiones partidarias de izquierda: Partido del Trabajo y del Pueblo, la corriente interna Tendencia del Partido Comunista y el Movimiento Democrático Popular Antiimperialista.

A lo anterior se sumaron otros efectos públicos que podríamos calificar de inesperados. Identificar a los militantes del MTP confirmaba que había sido una acción de la izquierda, tras lo cual se disparó una serie de eventos conmemorativos y homenajes a favor de los caídos: se 
decretó un día de duelo nacional, hubo homenajes en espacios oficiales y en diferentes establecimientos militares del ejército. En la ciudad de Córdoba se ofició una misa a solicitud de FAMUS20 en la iglesia Santo Domingo y en la localidad serrana de Cosquín se suspendió el tradicional festival de folklore para realizar una misa multitudinaria en la plaza Próspero Molina. ${ }^{21}$ Como sostiene Scott (2004), los rituales y homenajes cumplen un destacado rol. En este caso, entendemos que aportaron a relegitimar a las fuerzas armadas militares y policiales frente a la ciudadanía, al situarlos como víctimas de la acción "terrorista", restaurando las legitimaciones heridas que los alzamientos carapintadas habían promovido en su relación con la sociedad y parte de la clase política. Pero no solo se homogeneizó un consenso de repudio ante los acontecimientos de La Tablada y una consecuente relegitimación de las fuerzas represivas. Un efecto menos apuntado de aquellas violencias desplegadas fue el impacto en las militancias.

\section{La (re)estigmatización de las militancias}

Si se observan las declaraciones públicas, es correcto afirmar que estas mayoritariamente condenaron el uso de la violencia (como) política que los militantes del MTP volvieron a utilizar en los sucesos de La Tablada. Sin embargo, uno de los efectos menos trabajados de ese marco común de rechazos es la rápida configuración de un escenario estigmatizador -o de profundización de la estigmatización si se consideran acciones y escenarios previos; y en ese caso sería un (re)estigmatización- de las militancias, en parte como efecto de la actualización del pasado reciente que el uso de la violencia colectiva evocaba, pero también como una descalificación más genérica a ciertas modalidades del compromiso político que fueron catalogadas de ultras y/o extremistas para volver a delimitar, con Tilly, las fronteras entre las acciones políticas permitidas, toleradas y prohibidas. Desde que se conociera la filiación política de los militantes que ingresaron al cuartel, se disputaron públicamente las cercanías y lejanías de diferentes referentes y organizaciones al MTP, que incluyeron desde las denuncias de complicidades entre el gobierno y los atacantes hasta las adscripciones equivocadas y las solicitadas de autoexclusión. Así, por ejemplo, Franja Morada (nacional) fue acusada de vincularse con el atentado por haber participado de las campañas solidarias del café a Nicaragua ${ }^{22}$ y Carlos Menem acusó al gobierno radical de haber denunciado planes golpistas que incluían al peronismo y algunos referentes "carapintadas" y que el MTP había revelado previamente. En consecuencia, se produjo una ola de denuncias, descalificaciones, pedidos de retractación y declaraciones de rédito político en tiempo preelectoral. ${ }^{23}$

\footnotetext{
${ }^{20}$ Esta agrupación nucleaba a los familiares y amigos de "muertos por la subversión" y fue recurrente su acción en los años de la recuperación democrática, disputando sentidos acerca de los muertos producidos en la década anterior. Amparados en un discurso de reivindicación de la acción de las Fuerzas Amadas a las que entendían como beligerantes de una guerra contra la subversión, tuvieron presencia en la ciudad de Córdoba realizando misas, homenajes y publicando posicionamientos en la prensa comercial de la época.

${ }^{21}$ LVI, 30/1/1989, pp.1, 4.

${ }^{22}$ De hecho, Casella desmentía estas vinculaciones al destacar que la Coordinadora había cumplido en los años setenta un rol muy importante al alejar a los jóvenes de la "tentación guerrillera". LVI, 28/1/1989, p. 5.

${ }^{23}$ LVI, 27/1/1989, p. 1 y días subsiguientes.
} 
Por otra parte, comenzaron a visibilizarse posiciones que eran críticas con los sucesos de $\mathrm{La}$ Tablada y a la vez alertaban sobre cómo este acontecimiento era útil a lo que podríamos llamar la radicalización de las derechas. En efecto, sobre todo desde agrupaciones partidarias ubicadas a la izquierda del espectro ideológico, o en el progresismo como definición más laxa y amplia, pero también desde organizaciones que habían tenido un pasado más combativo que su presente -como la Federación Universitaria de Córdoba del año 1989- se denunciaban los peligros de un rebrote autoritario y, peor aún, del regreso del pasado cercano. ${ }^{24}$ Estas posiciones se sucedieron luego de conocerse, por un lado, declaraciones como las de los Tupamaros uruguayos que rompían la discursividad condenatoria ${ }^{25} \mathrm{y}$, por otro, de comenzar a hacerse públicas algunas inconsistencias en las versiones oficiales respecto del trato a los sediciosos y la ausencia de información sobre personas que continuaban desaparecidas o habían sido vistas entregándose con vida a las fuerzas represivas.

Considerando las repercusiones de esta irrupción en el escenario político, los organismos de derechos humanos, a nivel nacional, se mostraron preocupados por la ola de rumores que pretendía vincularlos por la antigua participación de uno de los referentes del MTP -Jorge Baños, quien resultara muerto- en el CELS. Esto no resulta sorprendente pues, si se considera la historia de un Movimiento de Derechos Humanos en Argentina que se había conformado en plena dictadura, su legitimación -como actores del proceso socio político- fue por demás costosa, al ser continuamente desacreditado por el poder dictatorial y, luego, criticado por sus posiciones maximalistas en democracia. Primero el CELS y luego el resto de los organismos hicieron declaraciones desligándose del hecho, pero fundamentalmente denunciando la ola de rumores que tenían por objeto deslegitimarlos a ellos y a sus luchas por supuestas conexiones con los militantes del MTP. Las declaraciones del CELS, del MEDH, de Madres de Plaza de Mayo e incluso del propio Ernesto Sábato defendiendo la labor de la CONADEP se inscriben en estas preocupaciones. Hebe de Bonafini, en ese momento ya referente de la fracción que se denominó Asociación de Madres de Plaza de Mayo, mostró su desconfianza con una versión oficial que servía al gobierno y a los militares al manifestar en la ronda de los jueves:

nos tenemos que preguntar cómo se gestó esto porque no nos van a hacer tragar este sapo que le están haciendo tragar a toda la dirigencia política [...] los torturadores y asesinos de ayer van a pasar a ser héroes, pero nosotros no los vamos a considerar nunca héroes. [Con relación a los efectos sobre las militancias] Nos quieren hacer creer ahora que esto no va a ser una caza de brujas, pero ¿acaso allanar 40 domicilios no es una caza de brujas?26 [Destacado mío].

En efecto, como alertaba la referente, los procedimientos llegaron prontamente a Córdoba, un lugar donde el MTP había tenido construcción política en el MoCo y que pese a haberse

\footnotetext{
${ }^{24}$ El comunicado de la FUC apuntaba que "esta situación pretende ser capitalizada por los mismos sectores fascistas que a lo largo de la historia despreciaron la voluntad popular, utilizando el terrorismo de estado para permitir que se impusiera una política de miseria sobre todo nuestro pueblo." LVI, 10/2/1989.

${ }^{25}$ La organización Tupamaros de Uruguay señaló que "se equivocaron gravemente" con el ataque, pero "son compañeros y pagaron con la vida", alertando sobre el uso que el fascismo haría de este hecho y reclamando solidaridad con el perseguido pueblo argentino. LVI, 29/1/1989, p. 5.

${ }^{26}$ LVI, 27/1/1989, p. 5.
} 
distanciado en 1987 de su proyecto, continuaba teniendo aquí militantes propios. En consecuencia, se allanaron dos locales, uno en la calle Jujuy 385 y el otro en Ramírez de Velazco 958 “donde [según la prensa] funcionaba el Movimiento Todos por la Patria y el Movimiento Cordobés, que adhería a esa expresión" con participación de la justicia y la policía federal, "sin resultados positivos" pero habiendo secuestrado documentación que no fue especificada. ${ }^{27} \mathrm{De}$ inmediato se conocieron comunicados de repudio y desresponsabilización de ambos nucleamientos. La Junta promotora del Movimiento Todos por la Patria declaró sentir confusión, angustia y consternación ante la noticia de que miembros del secretariado nacional habrían participado de La Tablada, rechazando y repudiando dichos actos y adelantando que, de confirmarse la noticia, harían presentación ante la Justicia Electoral para renunciar a sus cargos. Reafirmaban que no era su movimiento promotor de acciones violentas y que en caso de asonadas o levantamientos coincidían en la resistencia civil y mostraban su preocupación ante este hecho "que creemos aislado, sea para generalizar el terrorismo ideológico, la persecución política, la caza de brujas contra todas las organizaciones populares". ${ }^{28}$ En el caso del Movimiento Cordobés, el documento reproducido señalaba:

su más enérgico repudio al accionar de quienes en tales hechos han demostrado un desprecio total por la vida, la democracia y la vigencia de la Constitución, que constituyen hoy la única garantía para avanzar en la consolidación de las libertades fundamentales y la justicia social [por lo que rechaza] todo intento elitista y mesiánico, cualquiera sea su signo [pues] solo favorece a los sectores responsables de la aplicación del terrorismo de estado. ${ }^{29}$

En 48 horas estas posiciones eran ratificadas por su principal referente, Alejandro Ferreyra, en tanto secretario político del Movimiento Cordobés, mediante un nuevo comunicado a la prensa:

que en 1987 [el Movimiento Cordobés] se desvinculó totalmente del Movimiento Todos por la Patria. Entre los motivos que llevaron a tal determinación se destaca que existieron "serias disidencias políticas que significaban un cuestionamiento a la filosofía Vecinalista de nuestro Movimiento, su método de participación y elección de sus candidatos en asambleas barriales, incluyendo vecinos de distinta filiación política." [Y se aclara que frente a esta situación el movimiento] hizo las presentaciones legales pertinentes ante la justicia Electoral provincial a los fines de fijar nuevo domicilio. ${ }^{30}$

A medida que se desarrollaba la investigación, nuevas vinculaciones repercutían en Córdoba. Entre ellas, la detención del sacerdote Fray Antonio Puigjané, integrante del MTP que había participado activamente en la campaña del Movimiento Cordobés de 1987. El

\footnotetext{
${ }^{27}$ LVI, 28/1/1989, p. 1.

${ }^{28}$ LVI, 28/1/1989, p. 5, destacado nuestro.

${ }^{29}$ Ese peligro de hacer reverdecer la ideología que sostuvo la represión dictatorial también fue alertado por las autoridades nacionales del Partido Intransigente quienes advirtieron estar en contra de "cualquier intento de reinstalación de la doctrina de seguridad nacional y la creación del Consejo de Seguridad que reconoce la presencia institucional de las Fuerzas Armadas en áreas de gobierno". LVI, 28/1/1989, p. 5.

${ }^{30}$ LVI, 30/1/1989, p. 3.
} 
religioso fue detenido e imputado, aunque no participara presencialmente del ataque. En Córdoba se allanó el local del Sindicato Único de la Publicidad (SUP), también ligado a militantes del MTP y que antes fuera domicilio de los editores de la revista Entre Todos cuando se hacía desde Córdoba, justamente en el año 1987. ${ }^{31}$

Ese contexto de redefinición de las fronteras en cuanto a las actividades políticas impactó también al configurar en términos de amenaza ciertos modos de acción militante que eran ya habituales en alguna tradición política de izquierda, como los campamentos de verano. Es notable que tuvieron repercusión mediática nacional y efectos judiciales locales algunos de los realizados en Córdoba -para lo cual se reactualizaron imaginarios de tradiciones políticas perturbadoras o disociadoras del orden-. En particular, a partir de declaraciones de Alsogaray (UCD) denunciando que en Córdoba "se hacían campamentos de guerrilleros", y que además habrían estado allí integrantes del Movimiento Cordobés, a quienes identificaba igualmente como miembros del MTP, varias fuerzas debieron aclarar su desvinculación con los hechos de La Tablada y más genéricamente con la lucha armada. Patria Libre, surgida en 1987 con ex militantes de la izquierda en los setenta y un sector del Partido Intransigente, comunicó que había realizado un campamento en la localidad serrana de Salsipuedes, en los días previos a La Tablada, pero que no se hallaban allí militantes del MoCo. ${ }^{32}$ Frente a las denuncias, los dirigentes del Movimiento Cordobés se entrevistaron con el subsecretario de gobierno de la provincia para aclararles que no habían participado y que algunos sectores de la derecha estaban utilizando su antigua alianza política para responsabilizarlos $\mathrm{y}$, además, para volver a instalar a las fuerzas armadas como alternativa golpista. ${ }^{33}$

Otras agrupaciones que no habían tenido conexión con el MTP también resultaron sospechadas por sus actividades de formación política. El Partido Comunista de Córdoba fue investigado judicialmente por hacer un campamento en pleno momento de denuncias guerrilleras, ${ }^{34}$ solicitando luego un repudio del Consejo de los Partidos Políticos por cuanto el allanamiento a su campamento había dañado públicamente la "imagen de los comunistas, lo que motivó que se produjera un manto de sospecha sobre las actividades efectuadas por los militantes". ${ }^{35}$

Los efectos sobre la militancia continuaron, la Junta promotora del MTP en Córdoba se disolvió formalmente, mientras las indagaciones a los integrantes del Movimiento Cordobés

\footnotetext{
${ }^{31}$ Como en casos anteriores, el sindicato también emitió un comunicado condenatorio del ataque, al que calificaba como "categóricamente alevoso atentado a la democracia". LVI, 4/02/1989.

${ }^{32}$ LVI, 10/2/1989. El pedido de informes fue presentado por los diputados nacionales María Julia y Álvaro Alsogaray de la UCD y Alberto Natale, demoprogresista. En la denuncia se afirmaba que se había realizado en el campamento Bello Horizonte de Salsipuedes un evento con numerosos integrantes del Movimiento Cordobés. El dirigente de Patria Libre Isaac Rudnik aclaró que cerca de 100 personas de su agrupación habían participado de las actividades recreativas y de formación política en una coyuntura prelectoral nacional, en una instalación comercial pública, compartiendo la estadía con turistas.

${ }^{33}$ LVI, 10/2/1989.

${ }^{34}$ La noticia ocupó la primera plana del diario LVI el día 13 de febrero, como subnota de la principal que indicaba: "Indaga juez a militares que actuaron en La Tablada"; el título de la nota sobre el PC fue "Investigan campamento en Córdoba".

${ }^{35}$ LVI, 5/3/1989.
} 
se formalizaron. Luis Arias, apoderado del Partido Justicialista, pidió investigar a Alejandro y Santiago Ferreyra, dos de sus principales referentes, así como sus vinculaciones con el radical Carlos Becerra, al igual que la difusión de publicidad oficial en la revista Entre Todos, órgano del MTP. ${ }^{36}$ El procurador general de la Nación, Andrés D’Alessio, se reunió con Alejandro Ferreyra. En la oportunidad, el referente le entregó material sobre las actividades que el MoCo realizaba desde que se conformó como partido político municipal. Según lo publicado, el MoCo reafirmó su repudio a los hechos de La Tablada por haber afectado la vida democrática y por contribuir con sus nefastas consecuencias a la ofensiva de la ultraderecha. Por ello, como Movimiento reafirmaban su compromiso "con la democracia, la paz y las libertades políticas, y su decisión de seguir trabajando por la justicia social, auspiciando proyectos comunitarios y participativos como las cooperativas de trabajo". ${ }^{37}$

Estos efectos produjeron como impacto principal una profundización de la estigmatización pública de ciertas militancias, mediante efectos discursivos y acciones en las que confluyeron agencias estatales y la difusión de discursos legitimadores de estas provenientes principalmente de dirigentes políticos de diferente envergadura. En conversaciones informales, militantes del MoCo nos comentaron que volvieron a quemar volantes y papeles que podían comprometerlos en los inodoros, como hacían en los años setenta pre y dictatoriales; otros, optaron por alejarse de la ciudad y vivir un tiempo en casas prestadas, también reeditando viejas prácticas de seguridad y algunos otros directamente se desafiliaron. Ese clima de revival represivo fue muy desactivador, sobre todo para quienes habían militado y habían sido represaliados por el terror de Estado.

Ahora bien, las acciones y discursos estigmatizadores de ciertas militancias no eran nuevas en los años de la posdictadura y en general se entramaron en la problemática más amplia de la construcción de un conjuro contra las violencias, como hemos analizado en trabajos previos (Solis, 2011). Esto ha sido resaltado por otras investigaciones en las que se insiste, por ejemplo, en la persistencia de la teoría de los dos demonios como una explicación convincente de las violencias en el pasado dictatorial, en los decretos de juzgamiento a ambas cúpulas, militares y "guerrilleras", en los requerimientos a los testigos del Juicio a las Juntas al interrogarlos por su condición "subversiva" y, desde otras dimensiones, en la creciente disposición social y política a rechazar la violencia como política, la violencia colectiva y especialmente la lucha armada; disposición esta que se fue consolidando en aquella década y puede observarse en numerosas tomas de posición, conmemoraciones y discursos. ${ }^{38}$ Sin embargo, la difusión de marcos de interpretación y acciones estigmatizantes convivieron y se jalonaron con otra forma

\footnotetext{
${ }^{36}$ LVI, 24/2/1989.

${ }^{37}$ LVI, 25/2/1989.

${ }^{38}$ Aquí se articulan varios aportes de la historia reciente, algunos en clave de reconstrucción histórica y otros más asentados en el análisis de las memorias de la posdictadura y transición. Ver, por ejemplo, los trabajos individuales y colectivos de Feld y Franco, 2015; Franco, 2018; Crenzel, 2018, entre otros. Para las memorias de la militancia y aunque centrado en producciones circuladas desde los años noventa, destaco las reflexiones sobre la trasmisión entre generaciones y articulación de esas memorias en Oberti y Pittaluga, 2006. Sobre las condiciones de "salida" de las y los presos políticos en la posdictadura y los giros estigmatizantes, hemos desarrollado en extenso esta cuestión en el capítulo 2 de nuestra tesis doctoral, Solis, 2018.
} 
de recurrir a la violencia, como fueron los atentados y en particular los levantamientos militares de "carapintadas" que, desde Semana Santa de 1987, reeditaron las amenazas golpistas y destituyentes. Frente a esa recurrencia de la amenaza expresada en armas contra el poder civil, ciertamente los episodios de La Tablada, incluidos sus efectos e impactos aquí reseñados, constituyeron una novedad, una acción sorpresiva incluso dentro de círculos de cierta afinidad con su colectivo promotor. Este acontecimiento disruptivo ha sido uno de los principales inconvenientes a la hora de habilitar testimonios entre quienes participaron de la militancia barrial en los años previos, en particular de los que tuvieron vinculación con el Movimiento Cordobés. Incluso, en entrevistas y conversaciones exploratorias, el evento se ha convertido en una línea divisoria de aguas, a partir de los posicionamientos individuales y colectivos que animaron no solo sus integrantes sino un espectro más amplio de activistas que asumían posiciones progresistas y de izquierda por entonces. Desde quienes nos aseguraban que el MoCo estaba muy infiltrado por los servicios y por eso no valía la pena ser investigado, hasta los que defendían al MTP o lo defenestraban por los acontecimientos de La Tablada, incluidas las desacreditaciones vertidas contra quienes rápidamente se desafiliaron del MoCo con posterioridad a enero de 1989 e incluso las respuestas evasivas sobre la cuestión, resulta un elemento común la importancia que tuvo dicho acontecimiento para generar (o afirmar) posiciones. En ese sentido, para algunos de quienes habían participado activamente en el $\mathrm{MoCo}$, los sucesos de aquel verano tuvieron un fuerte impacto negativo en sus articulaciones políticas y principalmente en la legitimidad de sus acciones frente a quienes confiaban en su proyecto. A partir de entonces, debieron realizar diferentes diligencias administrativas, políticas y judiciales para demostrar que no habían tenido participación alguna en aquel evento. Así, mostrarse colaboradores con las investigaciones oficiales, publicar documentos de repudio y realizar entrevistas con altos funcionarios nacionales fue parte de las acciones que emprendieron sus referentes para lograr este objetivo.

Al cabo de algo más de un mes de permanente presencia mediática y de una larga etapa de instrucción, los detenidos por los acontecimientos de La Tablada fueron procesados y se les dictó la prisión preventiva, entre ellos a Puigjané, aquel colaborador activo de la campaña del MoCo en 1987. En medio de esa confirmación, las denuncias reiteradas de abusos, inconsistencias en las versiones oficiales y la falta de información fehaciente sobre el destino de algunos de los que habían participado de la incursión ponían en juicio la veracidad de las narrativas sólidamente difundidas, ${ }^{39}$ pero desde una posición marginal que no llegaba a desandar la construcción hegemónica de repudio a una acción interpretada como la reedición (descontextualizada) de la violencia guerrillera setentista. Desde la perspectiva institucional, el saldo inmediato fue la rediscusión acerca de las capacidades estatales para la seguridad interna, habiéndose conformado el $\operatorname{CONASE}^{40}$ que ponía a las fuerzas armadas en un lugar

\footnotetext{
${ }^{39}$ Los abogados defensores denunciaron malos tratos, traslados de prisioneros encapuchados, secuestros y fusilamientos. En un informe especial publicado por Infojus, se menciona a Provenzano y Samojedny como desaparecidos. Disponible en: http://www.infojusnoticias.gov.ar/latablada/ [consulta 10/2/2017] En la actualidad el número de desaparecidos asciende a cuatro.

${ }^{40} \mathrm{El}$ Consejo de Defensa Nacional estaba previsto en la estructura de defensa vigente en ese momento.
} 
institucional más expectable para redefinir los términos de sus participaciones en la vida interna del país y con un proyecto del Poder Ejecutivo de reforma legislativa, conocido como proyecto antiterrorista por parte de la prensa, en el que se propusieron cambios a la legislación penal vigente, a partir del episodio de La Tablada. Se trataba, pues, de un conjunto integral de cambios que proponían incluir modificaciones en el Código Penal, en el Código de procesamiento en materia penal y en la ley 23.077.41 Entre sus fundamentos, el proyecto de "ley ómnibus" -como publicitaba la prensa- afirmaba: “El reciente atentado criminal en La Tablada, produjo como una de sus consecuencias el análisis crítico de la legislación penal vigente." 42 Desde esa necesidad reconocida de ajustar la legislación, se proponía en el debate público aumentar penas por apología del delito, se contemplaba la alternativa de disminución o quita de pena a los subversivos que colaborasen en la aplicación de la ley penal y se castigaría a los que instigaran a cometer atentados contra el sistema. También se contemplaría la inadmisibilidad o apartamiento del defensor si hubiera participado de las actividades que se investigan, así como poder disponer el ejecutivo de fuerzas policiales para acciones represivas bajo responsabilidad federal. ${ }^{43}$ Si bien excede al presente artículo analizar las derivas y concreciones de tales iniciativas, se mencionan como indicadores de un arco de efectos más amplio que habría incluido la posibilidad de reformar procedimientos y normas de aplicación para casos similares.

\section{A modo de cierre}

Para las militancias otrora represaliadas por el despliegue del terror de Estado en dictadura (e incluso desde antes) la configuración de un tiempo nuevo, transicional y posdictatorial, implicó una serie de desafíos propios del momento posdictatorial, tensionando sus anteriores aprendizajes políticos en un escenario que había sido trastocado de manera profunda. En efecto, para quienes fueron sobrevivientes de la represión política, ese nuevo tiempo significó además convivir en un contexto donde se produjeron nuevas estigmatizaciones. De allí que la historia reciente de las militancias en la posdictadura precisa contener tanto la pregunta por los legados militantes y sus reconfiguraciones como el análisis de las interacciones contingentes que se produjeron en este tiempo.

En esa trama, el artículo se ocupó del haz de efectos y algunos de los impactos producidos por el acontecimiento La Tablada, ocurrido en enero de 1989, especialmente en el espacio de Córdoba y en relación con ciertas militancias emparentadas al grupo político responsable de aquel suceso. Dentro de este abanico de efectos públicos y políticos, identificamos un rechazo masivo y casi homogéneo frente a un nuevo intento de acción armada, que se replicó en espacios nacionales y locales y acendró un profundo y extendido rechazo a la violencia como política. A la par, advertimos operaciones y acciones de relegitimación respecto del uso de las

\footnotetext{
${ }^{41}$ Dicha ley, popularizada como ley de defensa de la democracia, fue publicada en el Boletín Oficial el 27 de agosto de 1984.

${ }^{42}$ LVI, 19/3/1989, p. 8.

${ }^{43}$ Ibídem.
} 
capacidades represivas estatales, que erosionaban esa anterior visión de fuerzas amenazantes, hasta avanzar -como otro efecto posible- en plantear el debate respecto al rediseño institucional de las penalidades.

Fuera de estos rechazos hacia el intento de copamiento y de los giros de legitimación de la represión contra el intento "desestabilizador", procuramos mostrar que, para ciertas militancias, la coyuntura creada en torno al acontecimiento y sus derivas mostraban indicios del fin de una época y el inicio de otra, aunque no ha sido recordado así generalmente. Por el contrario, en las memorias y en los análisis, fue la experiencia límite de la hiperinflación lo que ha demarcado la apertura de un tiempo nuevo. Sin opacar los efectos devastadores de la experiencia hiperinflacionaria, el artículo propuso una lectura de un evento contemporáneo que resultó también fuertemente desincentivador de la acción militante en ciertos grupos, mientras se suturaba un común rechazo a la violencia como política.

Por consiguiente, al haber puesto el acento en mostrar la relevancia de los acontecimientos en torno a $\mathrm{La}$ Tablada desde una perspectiva centrada en los vínculos entre militancias y procesos de democratización, cobró importancia reconstruir los efectos y el impacto producidos desde los discursos y las acciones de (re)estigmatización de las militancias ubicadas dentro de un universo político ideológico afín y/o cercano al grupo militante identificado como iniciador del evento, incluyendo además una cartografía más amplia de actores políticos y militancias organizadas. La contracara de esa estigmatización fue el retorno de discursos de legitimación de la acción represiva del Estado, aún atisbado el uso reiterado de metodologías afines al terror de Estado en democracia.

\section{Referencias Bibliográficas:}

Anzelini, L. (2019). Entre el discurso y la acción efectiva: las contradicciones de la política de defensa de Macri. Revista Científica General José María Córdova 17 (25), 69-90.

Celesia, F. y Waisberg, P. (2013). La Tablada A vencer o morir. La última batalla de la guerrilla argentina. Buenos Aires: Aguilar.

Ceresole N. (1989). La Tablada y la hipótesis de guerra. Buenos Aires: Editorial del ILTRI.

Crenzel, E. (2018). Enfrentando el retroceso. Justicia, verdad y memoria en la Argentina reciente. Águila, G. Luciani, L. Seminara, L. y Viano, C. La historia reciente en Argentina. Balances de una historiografía pionera en América Latina (pp. 129-150). Buenos Aires: Imago Mundi.

Feld, C. y Franco, M. (dir.) (2015). Democracia, hora cero. Buenos Aires: Fondo de Cultura Económica.

Franco, M. (2018). El final del silencio. Buenos Aires: Fondo de Cultura Económica.

Gorriarán, E. (2003). Memorias de Enrique Gorriarán Merlo: de los sesenta a La Tablada. Buenos Aires: Planeta.

Hilb, C. (2007). La Tablada: el último acto de la guerrilla setentista. Lucha Armada en Argentina (9), 4-22.

Mattini, L. (2003). Hombres y mujeres del PRT-ERP: la pasión militante. Buenos Aires: De la Campana. 
Montero, H. (2012). De Nicaragua a La Tablada. Una historia del Movimiento Todos por la Patria. Cuadernos de Sudestada 8, Buenos Aires: Peña Lillo - Ediciones Continente.

Oberti, A. y Pittaluga, R. (2006). Memorias en montaje. Escrituras de la militancia y pensamientos sobre la historia. Buenos Aires: El cielo por asalto.

Philp, M. (2009). Memoria y política en la historia argentina reciente: una lectura desde Córdoba, Córdoba: Editorial de la UNC.

Sain, M. (1994). Los levantamientos carapintada, 1987-1991. Vol. I y II, Buenos Aires: CEAL

Sain, M. (2018). ¿Los militares como policías?: Cambios en la seguridad en Argentina, 20132018. Nueva Sociedad 278, 36-47.

Scott, J. (2004[2000]). Los dominados y el arte de la resistencia. Discursos ocultos. México: Ediciones Era.

Solis, A. C. (2018). De la dictadura a las contiendas por la democratización. Reconfiguraciones de la militancia en la experiencia de Barrial y el Movimiento Cordobés (Tesis de Doctorado en Estudios Sociales de América Latina). Centro de Estudios Avanzados, Facultad de Ciencias Sociales, UNC, Córdoba.

Solis, A.C. (2011). Derechos Humanos en la Cultura Política desde la Acción Colectiva de una Democracia Excluyente. Córdoba entre 1989 y 2002 (Tesis de Maestría en Partidos Políticos). Centro de Estudios Avanzados, Facultad de Ciencias Sociales, UNC, Córdoba.

Tilly, C. (2006). Violencia colectiva. Barcelona: Hacer.

Tilly, C. (2007). Democracy. New York: Cambridge University Press.

Para citar este artículo:

Solis Ana Carol (2019). La Tablada en enero de 1989 y sus efectos e impacto en Córdoba. Sobre la (re) estigmatización de las militancias en la historia reciente. Anuario de la Escuela de Historia Virtual 15, 51-67. 